\title{
Isabelle Mayer-Michalon, Charles Meynier,
}

1763-1832

\section{Annie Duprat}

\section{(2) OpenEdition Journals}

Édition électronique

URL : https://journals.openedition.org/ahrf/11766

DOI : $10.4000 /$ ahrf. 11766

ISSN : 1952-403X

Éditeur :

Armand Colin, Société des études robespierristes

Édition imprimée

Date de publication : 1 septembre 2010

Pagination : 222

ISBN : 978-2-200-92633-5

ISSN : 0003-4436

Référence électronique

Annie Duprat, «Isabelle Mayer-Michalon, Charles Meynier, 1763-1832 », Annales historiques de la

Révolution française [En ligne], 361 | juillet-septembre 2010, mis en ligne le 22 mars 2011, consulté le 23 avril 2022. URL : http://journals.openedition.org/ahrf/11766 ; DOI : https://doi.org/10.4000/ahrf. 11766

Ce document a été généré automatiquement le 23 avril 2022.

Tous droits réservés 


\title{
Isabelle Mayer-Michalon, Charles Meynier, 1763-1832
}

\author{
Annie Duprat
}

\section{RÉFÉRENCE}

Isabelle Mayer-Michalon, Charles Meynier, 1763-1832, Paris, Arthéna, 2008, 328 p., ISBN 978-2-903239-39-8, $92 €$.

1 Le peintre Charles Meynier, dont l'œuvre, abondante, a été reconnue en son temps, est à présent tombé dans l'oubli, à un point tel que même sa tombe, achetée en concession perpétuelle en 1835 par un legs spécifique de sa veuve au cimetière du Montparnasse, a disparu par reprise administrative de la ville de Paris en 1974. Aucune voix alors ne semble s'être élevée contre un sort pareil.... Commencer le compte rendu de cet ouvrage par ces considérations prosaïques n'est pas innocent de notre part car il nous semble que la vie et l'œuvre de Meynier, même s'il n'a pas été un inconnu de son vivant, aura été marquée par l'ombre portée sur lui par les très grands artistes que furent David, Boilly, Gros ou encore Ingres, pour n'en citer que quelques-uns. Illustrateur de la geste napoléonienne, il a été redécouvert en 1974 lors de la fameuse exposition De David à Delacroix, et, plus récemment, lorsque plusieurs de ses œuvres ont quitté le domaine des collections privées pour entrer dans le marché de l'art et intégrer parfois les collections publiques. Tel fut le cas des décors faits pour l'hôtel particulier du négociant Boyer-Fonfrède à Toulouse dans les années 1980.

2 Né à Paris dans une famille de moyenne bourgeoisie, à une date encore difficile à déterminer (entre 1759 et 1768, l'auteur donnant des arguments en faveur de 1763), Meynier suit le cursus classique des candidats à l'Académie royale de peinture et de sculpture. Dès 1770, il se place sous la protection de François-André Vincent, le rival et ennemi de David; il obtient le Grand Prix de l'Académie en 1789 sur un sujet imposé, Joseph reconnu par ses frères. Il demeure en Italie entre 1790 et 1793, travaille beaucoup et rend toujours ses commandes à temps mais ne reçoit en échange que des jugements 
assez moyens de la part de ses professeurs. Après l'assassinat du chargé d'affaires français Hugues Basseville, en janvier 1793, et la mise à sac de l'Académie de France à Rome qui s'ensuit, Meynier perd tout, tableaux et couleurs, argent et objets personnels. Il part alors à Florence, puis retourne en France pour participer au Concours de l'an II. Dès lors, il ne cessera plus d'obtenir des commandes officielles ou privées (en particulier la Galerie des Muses pour l'hôtel de Boyer-Fonfrède, déjà évoquée). Entre 1800 et 1815, il est l'un des peintres chargés d'héroïser la geste napoléonienne (il réalise de grands décors pour la salle des Maréchaux aux Tuileries, s'illustre dans la représentation de tant de victoires napoléoniennes, Eylau et Austerlitz entre autres. Il était encore à la tâche lorsque survient la première restauration des Bourbons, ce qui l'oblige à modifier les allégories peintes sur ses décors pour le Louvre ou les Tuileries, transformant les emblèmes napoléoniens en emblèmes bourboniens. Prenons l'exemple d'une toile, La France recevant le roi de Rome transformé en La naissance de Louis XIV! Cette nécessité de continuer à honorer des commandes officielles alors que le commanditaire change du tout au tout lui vaut de figurer dans le Dictionnaire des Girouettes d'Alexis Aimery, avec un commentaire aussi sarcastique qu'immérité. Car c'est la modestie, la réserve et la timidité qui caractérisent Meynier d'après Isabelle Mayer-Michalon. Or, la plupart des noms cités dans le Dictionnaire des Girouettes sont ceux d'arrivistes polymorphes et versatiles.

3 Désormais, Dominique Vivant-Denon lui accorde sa protection. Durant les Cent-Jours, Meynier fait acte de candidature à l'Institut des Beaux-Arts le 27 avril 1815. Élu le 3 juin, il reçoit confirmation de cette élection le 10 juin 1815, just on time, pourrait-on écrire, pour ne pas risquer de se voir confisquer cette place honorifique, couronnement de sa carrière, une semaine plus tard, lorsque l'empereur est vaincu à Waterloo... Il continue à honorer de nombreuses commandes officielles, en particulier pour le Palais du Louvre, dans lequel il réside durant un moment avant d'installer son atelier et de prendre un domicile rive gauche, rue Monsieur le Prince. Il travaille également aux décors du palais Brongniart (l'ancienne Bourse de Paris) et pour le Musée Charles X, installé au premier étage de l'aile sud de la Cour Carrée du Louvre, mais aussi pour des commanditaires privés (en particulier l'hospice Boulard à Saint-Mandé). Mortellement frappé par l'épidémie de choléra en 1832, il décède en septembre. Il n'a pas laissé grand-chose à sa veuve, hormis de nombreux tableaux, et son éloge funèbre nous apprend que, s'il a participé à de nombreux jurys de concours - en particulier pour les prix de Rome - il n'a pas formé d'élèves. Est-ce pour ces raisons que sa mémoire est rapidement tombée dans l'oubli? Ses grandes compositions militaires, son esthétique et sa technique relèvent d'un genre que les nouveaux courants artistiques qui parcourent le XIX ${ }^{e}$ siècle, peinture "troubadour ", réalisme et impressionnisme ont vite démodé. Il a pourtant été apprécié et reconnu par ses pairs comme en témoigne sa présence sur les compositions de Léopold Boilly et de Marie-Gabrielle Capet figurant des réunions de peintres. Enfin, cet homme réservé est resté un ami fidèle à tous ses compagnons de l'Académie de France à Rome avec lesquels il avait vécu les dures journées de 1793.

4 Cette brève recension du livre d'Isabelle Mayer-Michalon ne saurait s'achever sans un hommage à la qualité de l'édition qui, d'une part, nous offre de très belles reproductions en quadrichromie et, d'autre part, réalise un catalogue raisonné de ses œuvres, assorti d'une très riche bibliographie des sources convoquées par l'auteur pour rédiger une thèse soutenue en 2005. Enfin, saluons le choix de l'illustration de 
couverture, Clio, muse qui préside à l'Histoire, allégorie destinée à la Galerie des Muses de l'hôtel Boyer-Fonfrède, actuellement conservée à Cleveland.

\section{AUTEURS}

\section{ANNIE DUPRAT}

FR 